\title{
VELOCITY CONTRAST ACROSS THE SAN ANDREAS FAULT IN CENTRAL CALIFORNIA: SMALL-SCALE VARIATIONS FROM $P$-WAVE NODAL PLANE DISTORTION
}

\author{
By Karen C. MeNally* and Thomas V. MeEvilly
}

\begin{abstract}
Systematic variations in $P$-wave radiation patterns, evident in a data set of 400 central California earthquakes, have been analyzed for variations in velocity contrast across the San Andreas fault zone. Vertical strike-slip faulting characterizes the region, with radiation patterns well constrained by the dense local seismographic station network. A discontinuity in crustal velocity occurs across the San Andreas fault. The distribution of systematically inconsistent first motions indicates that first arrivals observed along the fault plane within the northeastern block have followed refracted paths through the higher velocity crustal rocks to the southwest, retaining $P$-wave polarities characteristic of the quadrant of origin, and thus appearing reversed. A simple geometrical interpretation, with $P$ waves refracted at the fault plane near the focus, yields the velocity contrast across the fault zone; the distribution of hypocenters allows its mapping in time and space. The velocity contrast so determined ranges up to 15 per cent, for a depth range of 1 to $10 \mathrm{~km}$. The observed pattern of contrast values is coherent, with the greatest contrast related apparently in space, and possibly in time, to the larger earthquakes occurring on the fault. We suggest the phenomenon reflects changes in stress state at the fault and, by virtue of its ease of measurement, offers a new and valuable technique in earthquake studies.
\end{abstract}

\section{INTRODUCTION}

The high density of seismographic stations in central California allows routine determinations of well-controlled $P$-wave fault plane solutions for earthquakes larger than $M_{L} \simeq 2$. Hundreds of such observations along a $40-\mathrm{km}$ segment of the active San Andreas fault system in San Benito County reveal a pattern of systematic variations in inconsistent first motions near nodal planes, apparently due to lateral refraction of $P$ waves along the fault zone. The effect ranges from small (within $5^{\circ}$ resolution) to relatively large $\left(30^{\circ}\right)$ across the region. The patterns are analyzed here for evidence of spatial and temporal variations in velocity contrast at the fault plane.

Earthquakes used in this study are shown in Figure 1. They have been relocated systematically using a uniform station set with station time adjustments, and have a relative location accuracy of less than $0.5 \mathrm{~km}$ (McNally, 1978a). The residual location bias to the southwest probably results from inadequate modeling of the lateral velocity change across the San Andreas fault zone (McEvilly, 1966). In Figure 2, the earthquakes are viewed in a depth section along the fault plane $\mathrm{NW}$, to $\mathrm{SE}, \mathrm{A}$ to $\mathrm{A}^{\prime}$, and $\mathrm{SW}$ to $\mathrm{NE}, \mathrm{B}$ to $\mathrm{B}^{\prime}$. In Figure 3 , the earthquakes occurring along the main fault trace between latitudes $36^{\circ} 34.5^{\prime} \mathrm{N}$ and $36^{\circ} 36.0^{\prime} \mathrm{N}$ are shown in a depth section crossing the fault zone. These hypocenters are distributed along a vertical zone of faulting between depths of 1 to $10 \mathrm{~km}$ which is less than $\frac{1}{2} \mathrm{~km}$ wide. As the zone width is the same as the relative uncertainty in hypocenter position, the possibility remains that the earthquakes are, in fact, located on a plane.

*Present address: Seismological Laboratory, California Institute of Technology, Pasadena, California 91125 . 


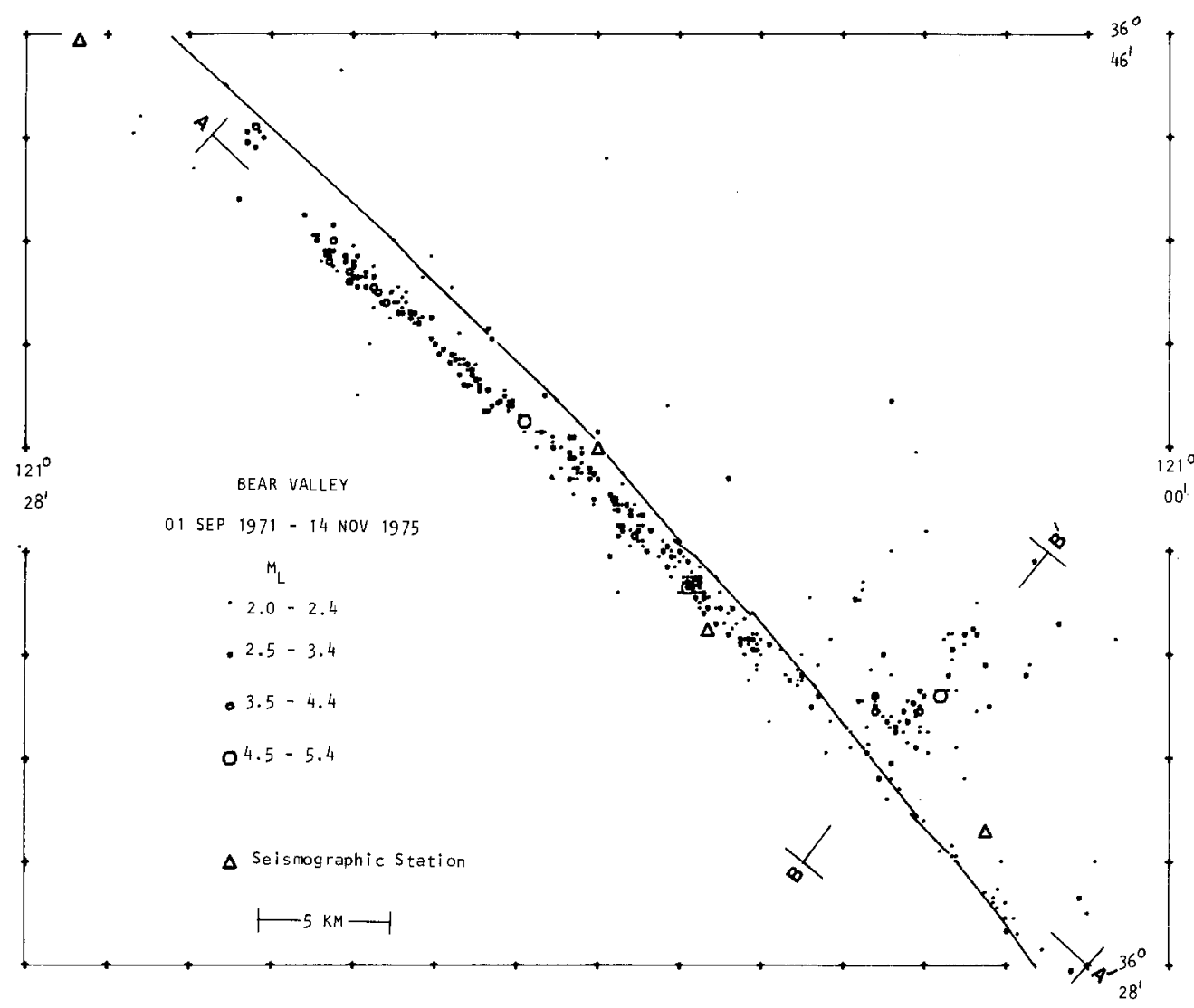

FIG. 1. Seismicity of Bear Valley/Stone Canyon study region, 1971-1975. Fault trace and cross sections in Figure 2 are indicated.

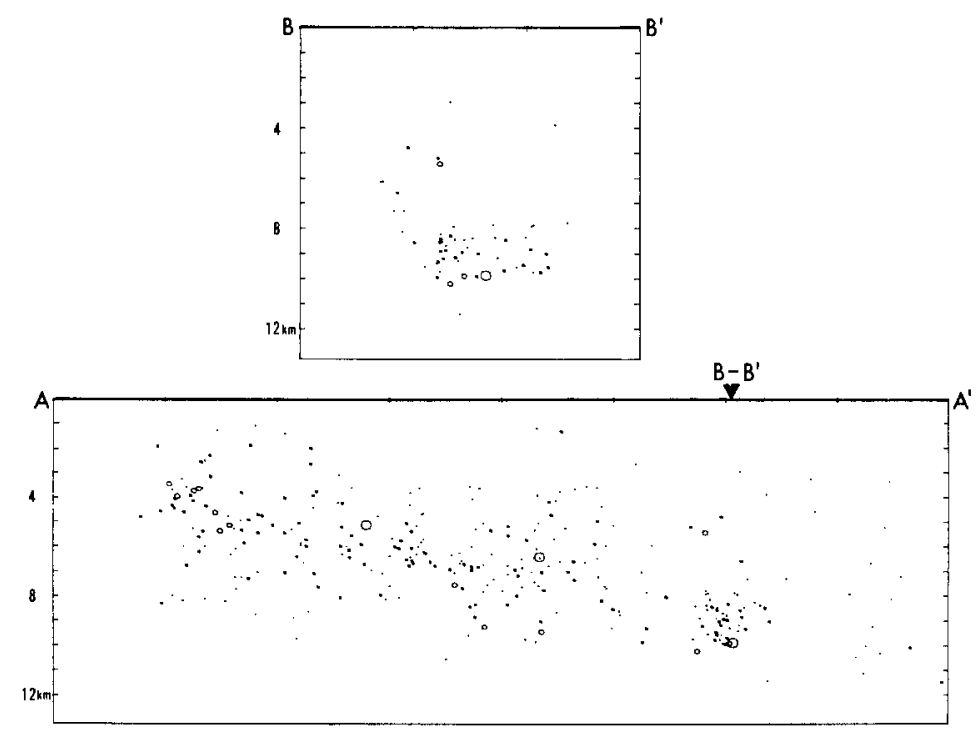

FIG. 2. Cross sections of hypocenters along and normal to the fault. Section locations and magnitude symbols are given in Figure 1. 
Several studies have been concerned with the local crustal velocity structure in this region: McEvilly (1966), Stewart (1968), Boore and Hill (1973), Healy and Peake (1975), McEvilly and Clymer (1975), Aki and Lee (1976), Engdahl and Lee (1976), and $\operatorname{Lin}(1977)$. In general, these studies have yielded estimates of lateral velocity contrast across the San Andreas zone of 5 to 20 per cent between depths of 1 and 10 $\mathrm{km}$, the granitic section to the southwest being of higher velocity than the adjacent Franciscan rocks northeast of the San Andreas zone.

\section{DATA}

Two types of $P$-wave first motion displays have been used in the analysis of radiation patterns. The conventional equal area projection of the upper focal hemisphere uses a $22-\mathrm{km}$ thick crust with velocity varying as $5.15+0.06 Z \mathrm{~km} / \mathrm{sec}(Z$ is depth in $\mathrm{km}$ ) overlying $7.84 \mathrm{~km} / \mathrm{sec}$ mantle. For vertical strike-slip mechanisms, nodal lines are radial and solutions are not seriously affected by model errors, except for lateral

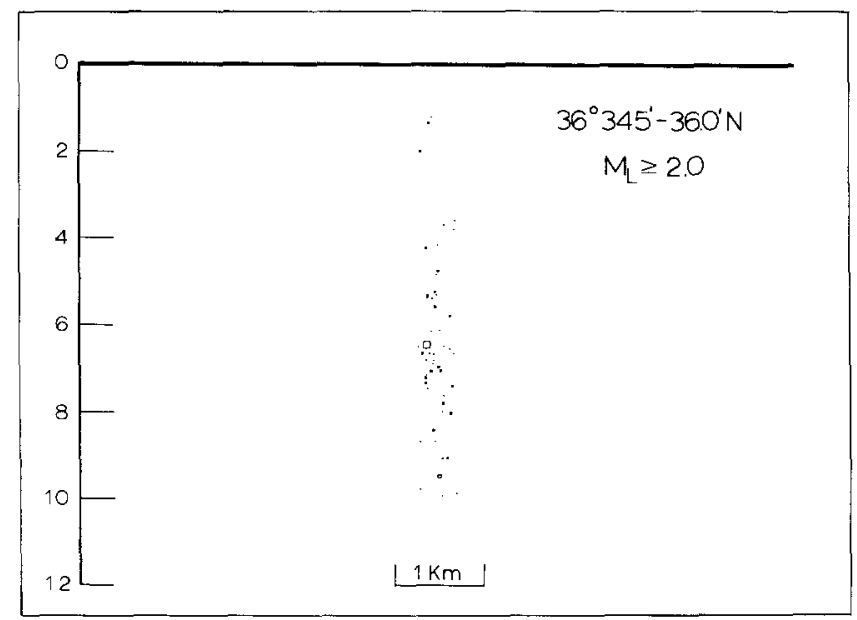

FIG. 3. Cross section across fault at $36^{\circ} 34.5^{\prime}$ to $36.0^{\prime}$, showing narrow vertical fault plane.

velocity changes. In the second type of display used, a map of near-station polarities is plotted relative to the earthquake epicenter. Vertical strike-slip faulting produces a simple four-quadrant pattern centering on the epicenter. Examples of the two displays are given in Figure 4 for an earthquake with minimal first-motion inconsistencies. A study of more than 200 mechanisms in the study area, utilizing equal area projections, revealed only one or two earthquakes on the San Andreas fault apparently different from strike-slip motion on a vertical plane, substantiating the pattern seen in the cross section of hypocenters in Figure 3. Using both types of display, the study was expanded to include over 400 earthquakes of $M_{L} \geqq 2.0$ from 1969 to 1976. In Figure 5, a number of nodal planes determined from standard (nondetailed) equal area projection methods and adopted as fault planes are displayed for the study region. The strike of these fault planes was further refined from composite analysis of auxiliary nodal planes as a function of latitude for all earthquakes occurring along the main fault trace, using approximately 20 stations. The strike thus found is uniformly $\mathrm{N} 43^{\circ}$ to $44^{\circ} \mathrm{W}$ between latitudes $36^{\circ} 31.6^{\prime} \mathrm{N}$ and $36^{\circ} 40^{\prime} \mathrm{N}$. North of $36^{\circ} 40^{\prime} \mathrm{N}$ the strike shifts more westerly to $\mathrm{N} 47^{\circ}$ to $48^{\circ} \mathrm{W}$. Between $36^{\circ} 29^{\prime}$ and $36^{\circ} 31.6^{\prime} \mathrm{N}$, the strike is not well constrained, but is more northerly than $\mathrm{N} 44^{\circ} \mathrm{W}$. (Strikes shown in Figure 5, based only on cursory analyses of equal area projections do not reflect this uniformity). 
Within the detail of the first-motion patterns, wedges of inconsistent polarities along the fault plane are observed frequently in both northeast quadrants. Examples are shown in Figures 6 and 7. These deviations within the radiation patterns are not

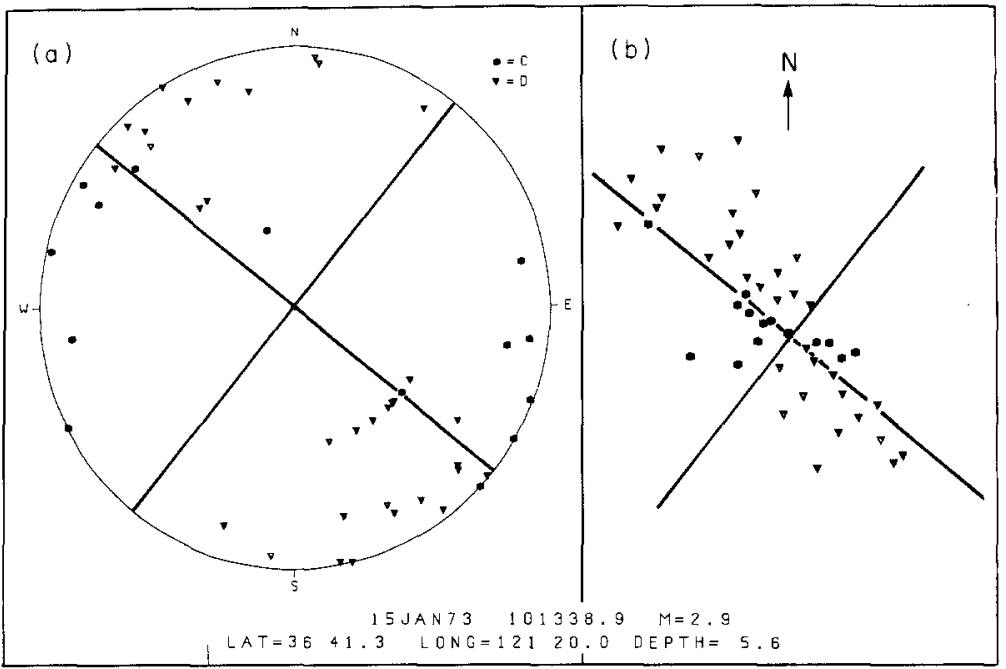

FIG. 4. Left, upper hemisphere equal-area projection of $P$-wave polarities. Right, "flat" display of same polarities in map form.

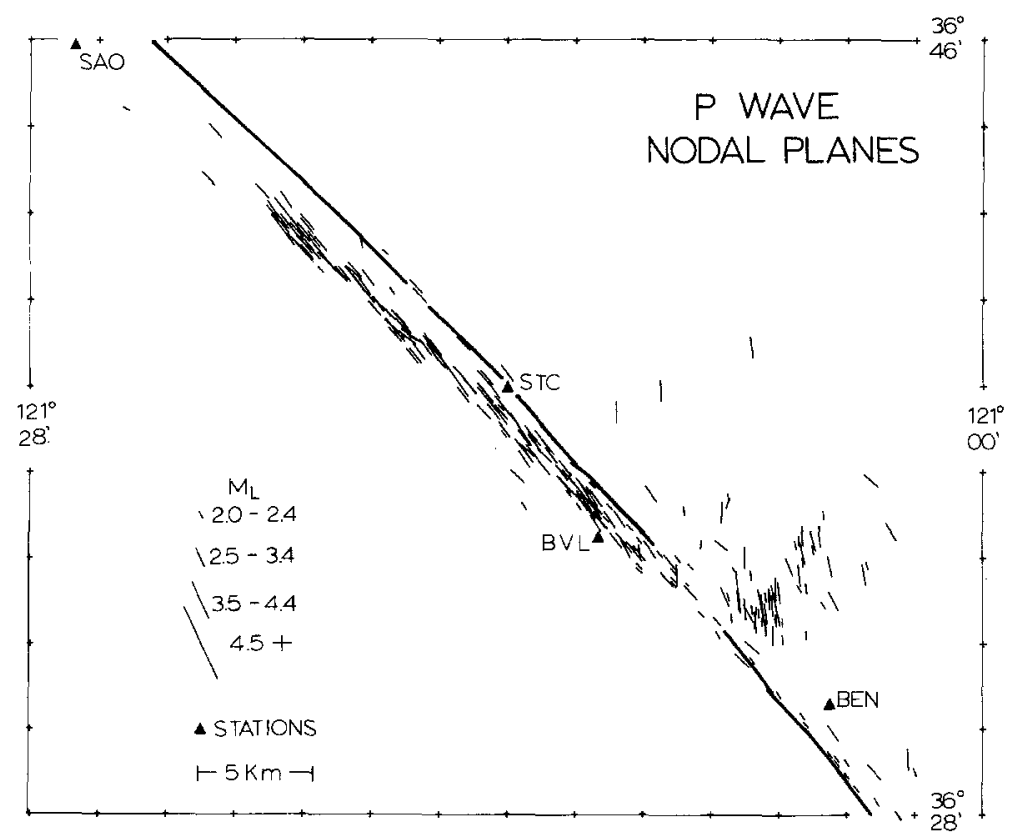

FIG. 5. Fault planes determined for a large group of earthquakes using equal-area projections.

consistent with plane faulting models (including a dipping fault model) in a medium without lateral velocity variation. The strike of the fault plane is well constrained from analysis of the auxiliary nodal planes. The spatial extent of the inconsistencies is found to be variable for earthquakes throughout this region. Examples of variation are seen in Figure 4 (inconsistencies nearly absent, within $5^{\circ}$ resolution) and Figures 


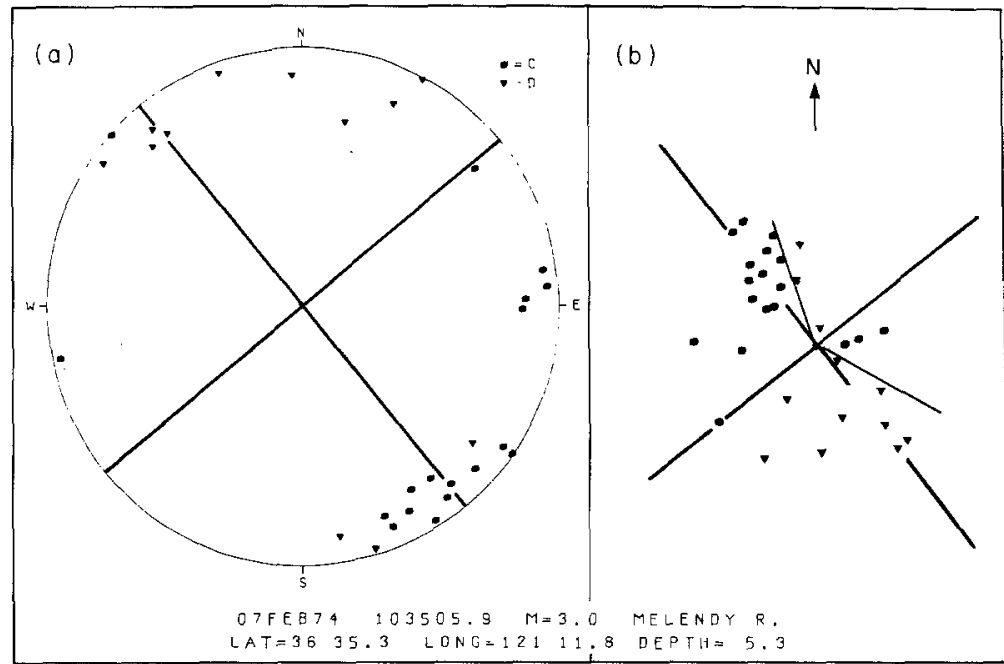

FIG. 6. Left, upper hemisphere equal-area projection showing distorted nodal plane. Right, "flat" display of the same data.

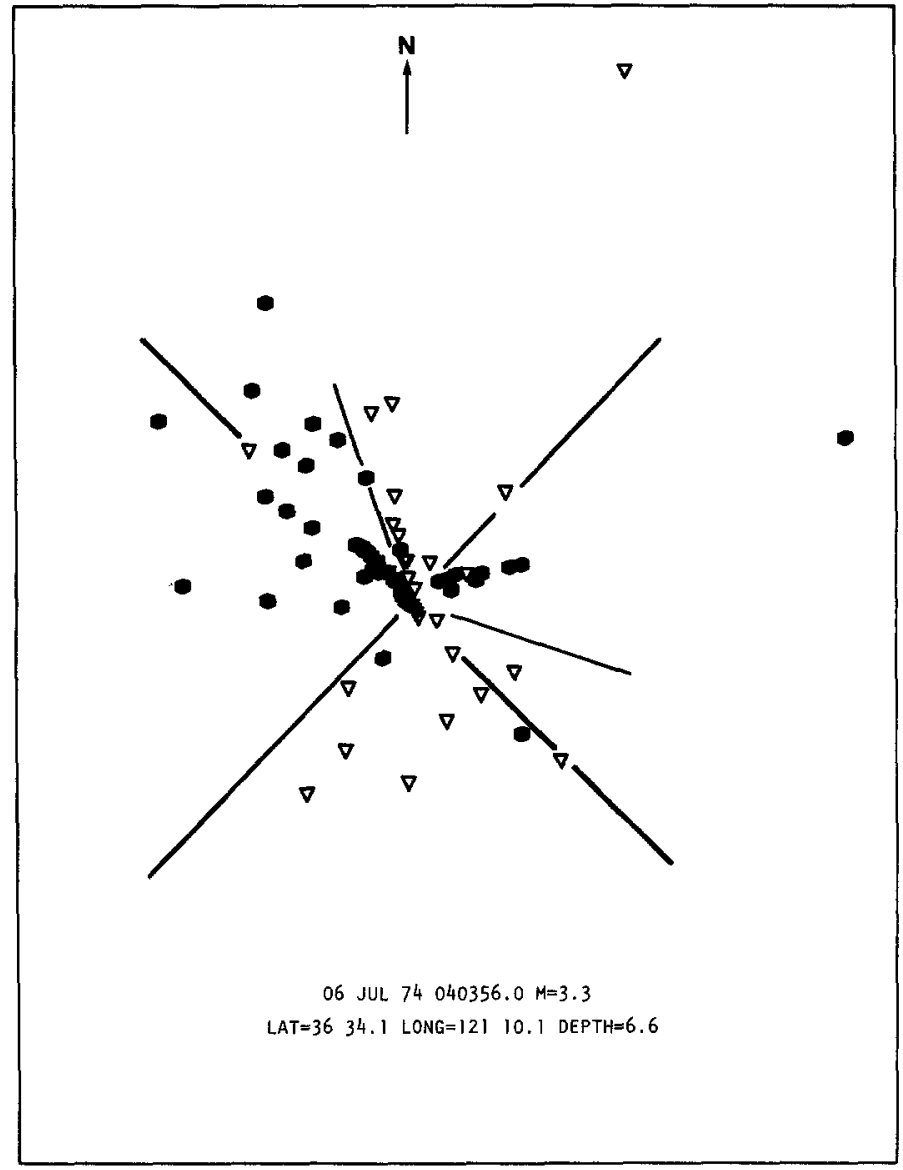

FtG. 7a

Fig. 7. Examples of distorted nodal plane patterns in "flat" display. 


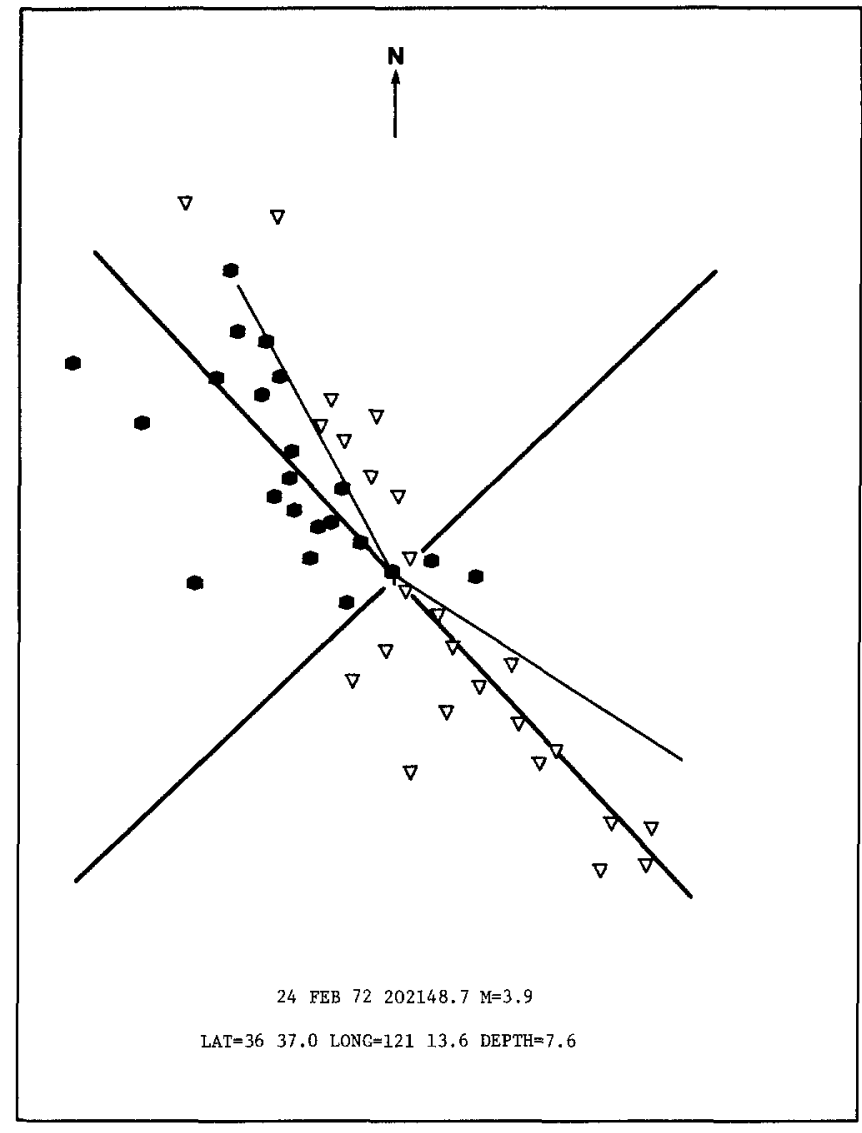

FIG. 7b

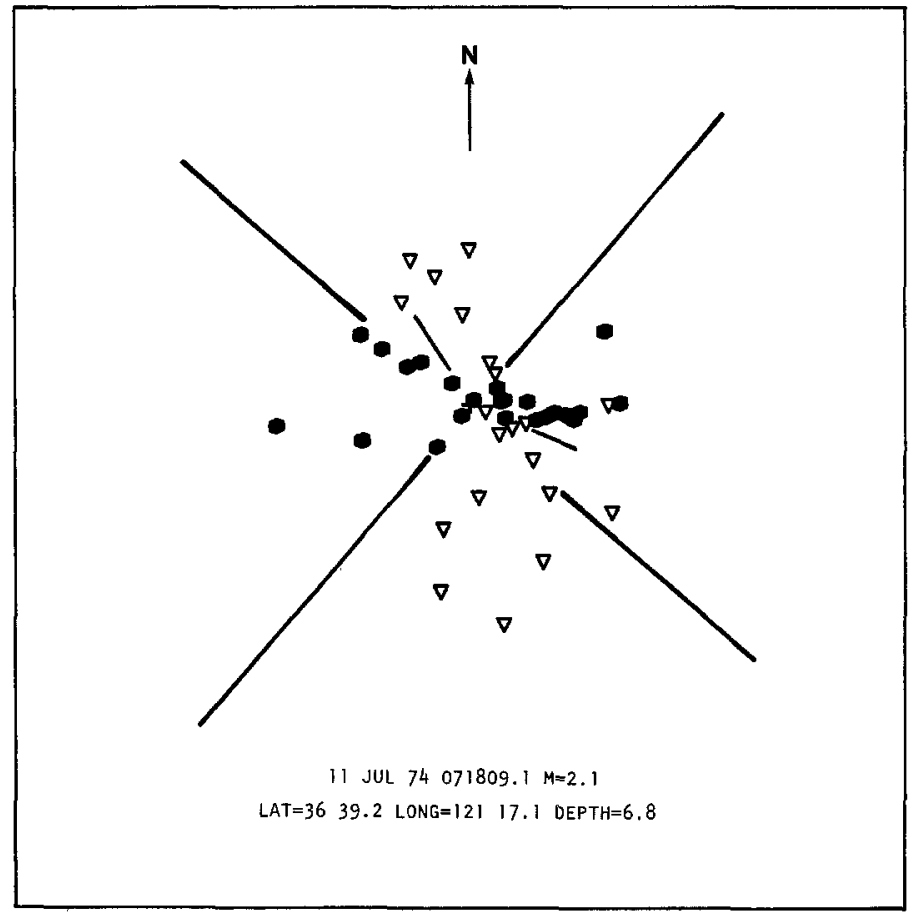

FIg. 7e 
6 and 7 . Inconsistent polarity patterns, when present, are apparent always as wedges along the fault strike in the NE quadrants. This study represents an attempt to document and analyze these perturbations in radiation patterns. We have measured the extent of the wedges of inconsistent first motions relative to a reference strike (controlled by the composite analysis of auxiliary nodal planes) for all earthquakes occurring along the main fault trace. (The results are shown contoured in Figure 9, discussed below).

Exhaustive checking of USGS instruments has eliminated polarity reversals as possible cause of the systematically inconsistent first motions; the division of first motions with these perturbed nodal planes is generally sufficient to disregard the very few remaining stations with inconsistent polarities. In addition, both the presence and absence of anomalous first motions at greater distances are well documented at the University of California, Berkeley, seismographic station at Mt. Hamilton, which lies in the NE quadrant and is not subject to polarity reversals. There is no indication that the effect observed is related to magnitude (i.e., strength of first arrival), with clear patterns seen across the array for events as small as $M_{L}=2$ and up to $M_{L} \simeq 5$. Station coverage is sparse in the southeast quadrant, but station HER, which lies in this quadrant and has not been subject to polarity reversals provides clear indications of both consistent and inconsistent first arrivals. Measurements made at this station are also confirmed by supplemental data in this quadrant during dense portable array coverage (Healy and Peake, 1975).

\section{INTERPRETATION}

A simple geometrical interpretation of the observed distorted pattern of first motions is based on two media of differing velocities in contact at the fault plane as shown in Figure 8, where $V_{1}<V_{2}$. The loci of equal travel times of direct and critically refracted arrivals are two lines diverging from the contact at angle $\theta$, where $\theta=\cos ^{-1}$ $V_{1} / V_{2}$. Note also that the refracted arrivals along the distorted nodal plane have, in fact, virtually their entire propagation path within the lower velocity medium, having been influenced by the velocity contrast only in the immediate vicinity of the source. In other words, even if the contrast in velocity diminishes along the fault away from the source, the nodal plane will maintain the same distortion angle, $\theta$, because of the time advance provided the refracted wave in the source vicinity. Of course, the amplitudes of first arrivals within the anomalous wedge will depend on variations in the contrast away from the source, but the polarity will remain reversed. Subsequent studies should investigate amplitudes, but the characteristics of the present instruments are not ideally suited for such studies.

The distribution of inconsistent first motions in the fault-plane solutions was investigated by measuring the angle $\theta$ from the strike of the reference fault plane to the stations (see Figures 6 and 7). The range of $\theta$ observed is from $0^{\circ}$ to something greater than $27^{\circ}$, corresponding to values of $V_{1} / V_{2}$ of 0.89 or less, from the above relation. The angle of apparent refraction, $\theta$, is variable along the fault plane and is not found to be systematic with source depth. Measurements of $\theta$ are plotted in Figure 9 on the fault plane at the position of the earthquake for which they were determined. The change in strike of the reference fault plane north of $36^{\circ} 40^{\prime} \mathrm{N}$ has been taken into account in the measurements of $\theta$.

The greatest angles of refraction occur between $36^{\circ} 34^{\prime} \mathrm{N}$ and $36^{\circ} 40^{\prime} \mathrm{N}$ in the central region of the seismic activity (Figure 1), with inferred velocity contrast of 10 to 15 per cent. The very highest values of velocity contrast are found $36^{\circ} 34^{\prime} \mathrm{N}$ to $36^{\circ} 38^{\prime} \mathrm{N}$ 


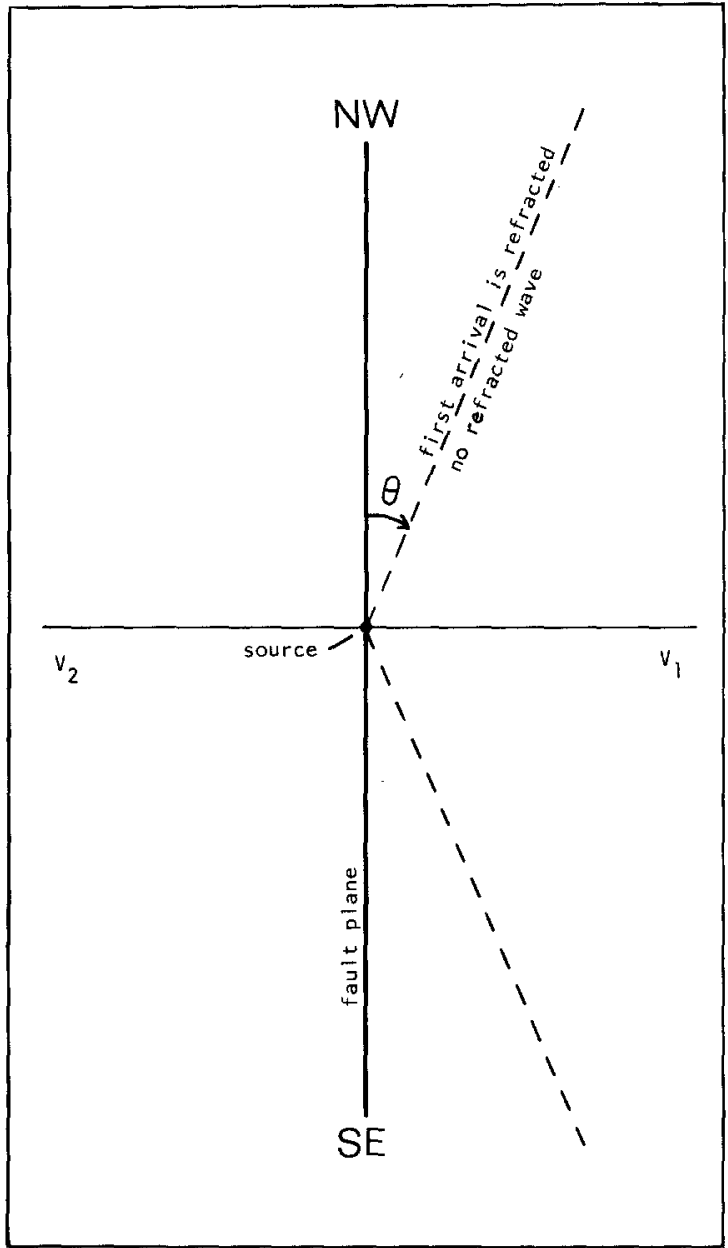

Frg. 8. Schematic of the measured angle, $\theta$, of nodal plane refraction.

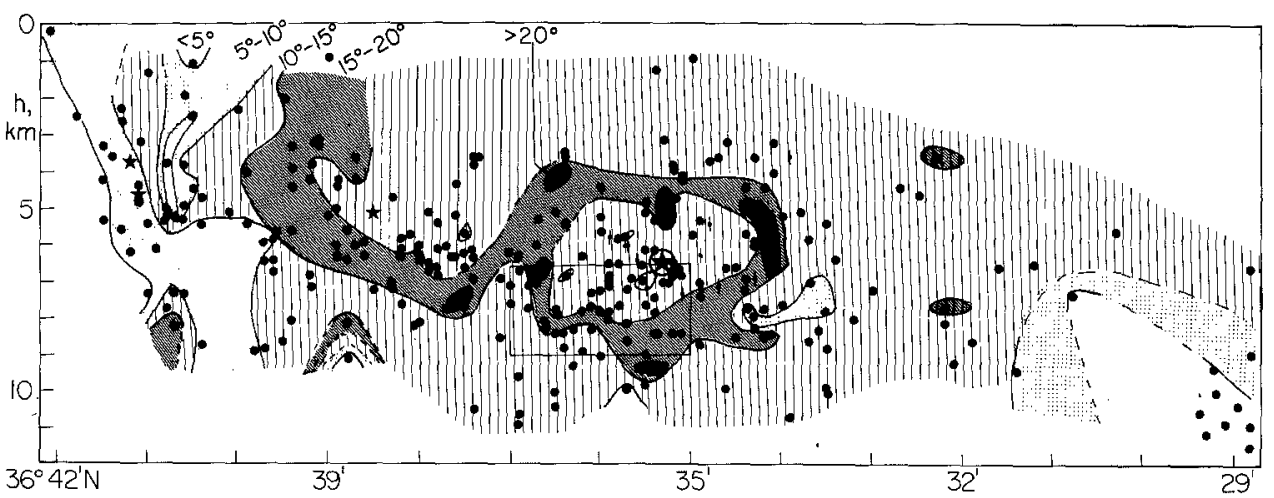

Fig. 9. Contoured values of $\theta$ in the fault plane. Stars indicate hypocenters of larger earthquakes (see text for discussion of relevance). Rectangle delineates area shown in Figure 10.

and ring the hypocenter of the $M_{L}=5.1$ earthquake of February 24, 1972, the largest earthquake to occur in this region since 1961 , shown at latitude $36^{\circ} 35.3^{\prime} \mathrm{N}$. (Three other moderate-size earthquakes, $M_{L}=4.0,4.7$, and 4.1, occurring in the sequence of activity in 1971,1972 , and 1973 , are also shown, at latitudes $36^{\circ} 41.2^{\prime} \mathrm{N}, 36^{\circ} 38.5^{\prime} \mathrm{N}$, 
and $36^{\circ} 41.1^{\prime} \mathrm{N}$, in Figure 9.) The aftershock zone of the $M_{L}=5.1$ developed only to the north, to latitude $36^{\circ} 38^{\prime}$. It is of interest that this ring of highest refraction also encircles an anomalous pattern of earthquake clustering observed in the long-term areal seismicity (1962 to 1971), prior to the $M_{L}=5.1$ earthquake (McNally, 1978b, and $1978 \mathrm{c}$ ). The degree of refraction decreases to the northwest between latitudes $36^{\circ} 40^{\prime} \mathrm{N}$ and $36^{\circ} 42^{\prime} \mathrm{N}$, as a region of lower seismicity (Figure 1) is approached. Although data are sparse, there is evidence that the refraction effect decreases also to the southeast, again into a region of diminished seismicity. It thus appears that the velocity structure at the fault plane is rapidly varying in space, and is related to the large earthquakes.

A rough estimate of the extent of temporal changes is possible with the data near the $M_{L}=5.1$ earthquake (the zone outlined in Figure 9 between latitudes $36^{\circ} 35^{\prime} \mathrm{N}$ and $36^{\circ} 37^{\prime} \mathrm{N}$ ), shown separated before and after this event in Figure 10. In the figure,

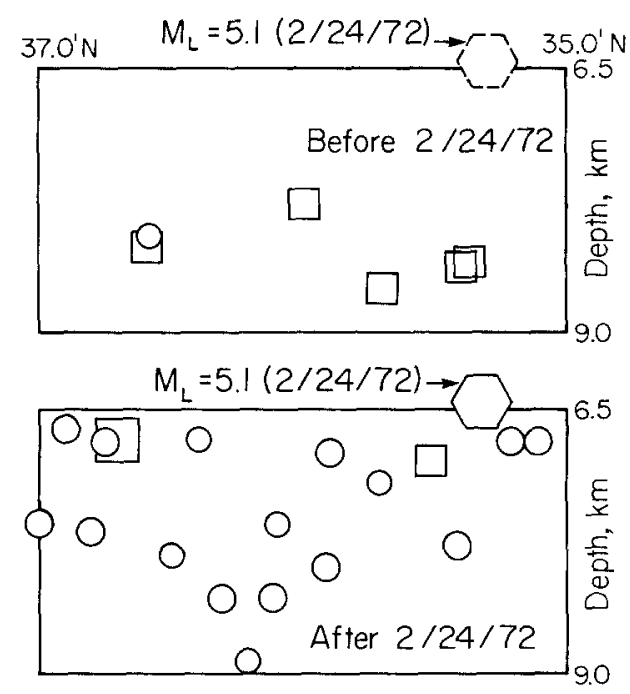

FIG. 10. Proximate nodal plane refraction observations before and after the largest $\left(M_{L}=\mathbf{5 . 1}\right)$ earthquake during the study period. Squares and circles indicate $\theta>15^{\circ}$ and $\theta<15^{\circ}$, respectively.

symbol types indicate only the upper half range $\left(\theta>15^{\circ}\right)$ and the lower half range $\left(\theta<15^{\circ}\right)$ of refraction angles. It appears that prior to February 24,1972 the events were generally deeper with large angles of refraction; following the February 24, 1972 shock, earthquakes with small refractions were observed over all depths 6.5 to 9.0 $\mathrm{km}$, with the two larger refraction events occurring at shallower depths. It is an attractive hypothesis that the velocity contrast is sensitive to local stress concentration, and thus diminishes following large earthquakes which relieve the locally high stress.

\section{Discussion}

The range of values for velocity contrast obtained by this analysis, up to 15 per cent between 1 and $10 \mathrm{~km}$ depth, are in agreement with models proposed in other studies based on geological and refraction studies (Engdahl and Lee, 1976; Stewart, 1968), reflection studies (McEvilly and Clymer, 1975), $P$ - and $S$-wave arrival time analyses (McEvilly, 1966; Boore and Hill, 1973; Healy and Peake, 1975; Aki and Lee, 1976), and laboratory studies ( $\operatorname{Lin}, 1977$ ). The effect of lateral $P$-wave refraction 
at the fault plane has been investigated by Engdahl and Lee (1976) using ray tracing techniques and local observations for three earthquakes in the area. Their model, however, does not consider the larger field of data at greater distances used in this study. Aki and Lee (1976) have found a general pattern of high velocity to the SW and low velocity to the NE through the area of highest refraction found in this study. The spatial resolution of their method, however, does not allow a more detailed comparison.

The lower range of values for velocity contrast found, up to 3 per cent between 1 and $10 \mathrm{~km}$, are somewhat less than generally expected from field observations or laboratory experiments on representative rock types. The crustal rocks in contact at the San Andreas fault in this region are the Franciscan formation on the northeast (about 80 per cent graywacke by volume), and granite on the southwest. Laboratory results of Birch (1960) indicate a $P$-wave velocity of $6.31 \mathrm{~km} / \mathrm{sec}$ for Butte, Montana, granodiorite at a pressure of 2.3 kilobars, considering temperature effects at $200^{\circ} \mathrm{C}$ (Birch, 1958). [The temperature and pressure selected here for velocity calculations are based on approximate values at a depth of $7 \mathrm{~km}$ (Lachenbruch and Sass, 1973)]. Lin (1977) finds a $P$-wave velocity of $6.03 \mathrm{~km} / \mathrm{sec}$ for Mt. Diablo high-grade metamorphosed graywacke at a pressure of 2.3 kilobars, considering temperature effects. For Marin County low-grade graywacke, Lin finds a $P$-wave velocity of $5.20 \mathrm{~km} / \mathrm{sec}$ at the same temperature and pressure. These values lead to a range of velocity contrast for similar rock materials in San Benito County of 4 to 18 per cent, depending on the grade of graywacke selected. It seems, therefore, that the presence of highgrade metamorphosed graywacke, along with a minor reduction in the granite velocity (cracks and/or pore pressure), can explain the lower values of velocity contrast inferred. The higher refraction values would call upon significantly reduced velocities within the Franciscan rocks. It is not possible to explain these observations by assuming a uniform vertical zone of low-velocity fault gouge. The width of the zone of hypocenters is constrained to be $<200$ meters, based on travel-time difference of $< \pm 0.05$ sec at PRS and LLA (two seismographic stations on opposite sides of the fault) for events at the same latitude (within our reading uncertainties, the hypocenters may lie in a plane).

We suggest that the apparent variations in velocity contrast may reflect variable stress concentration in the region, i.e., that the variations in contrast of physical properties correlate with variations in deformation at the fault, assuming that the lithologies (including grade of metamorphism) are approximately constant. Both the high level of seismicity and the high rate of aseismic fault slip (Nason, 1973) are reflections of ongoing strain fluctuations along this segment of the San Andreas fault zone. Additional evidence is required to specify whether the spatial variation in velocities occurs predominately in the granite or in the Franciscan rocks. Microfracturing related to the failure process at the fault plane is a plausible mechanism for variation. Differences in porosity or pore fluid content are others.

\section{CoNCLUSIONS}

The existence of dense network coverage allows the clear identification of a systematic pattern of inconsistent $P$-wave first motions within the radiation patterns of small earthquakes on the San Andreas fault in San Benito County. The patterns are interpreted in terms of lateral refraction of first arrivals through the higher velocity granitic rocks southwest of the fault, and these imply local variations in velocity contrast of up to 15 per cent across the fault. If these inconsistent first motions are due to 
refraction as inferred, seismologists have access to new information regarding crustal conditions on a fine scale near the earthquake source. It seems particularly important to understand the observed variability of this effect along the fault plane, and its apparent relation to the larger earthquakes on the fault. We suggest that these patterns indicate exaggerated velocity contrasts related to local stress state near the source regions of earthquakes of moderate size. If the apparent contrast, as seen in the refraction angle, can be established to be a function of time, its observation offers a novel and powerful technique for monitoring stress-related velocity changes within the earthquake source region. A few simple, tightly-spaced $(0.5 \mathrm{~km})$ linear arrays of seismometers, 5 to $10 \mathrm{~km}$ long and normal to the fault would provide sufficient resolution to see variations of $1^{\circ}$ to $2^{\circ}$ in the apparent refraction angle, and thus to monitor changes of 1 per cent or more in the velocity contrast at the fault. Adequate calibration and dynamic range would also provide needed data on amplitude variations for further refinement of the analysis of this interesting and potentially valuable phenomenon.

\section{ACKNOWLEDGMENTS}

This research was supported by the Advanced Research Projects Agency and was monitored by the Air Force Office of Scientific Research under Contract F44620-75-C-0049, as part of a cooperative study of the near-field characteristics of small earthquakes. Data from the USGS central California network stations were kindly made available by Menlo Park personnel. C.I.T. Contribution No. 2926.

\section{REFERENCES}

Aki, K. and W. H. K. Lee (1976). Determination of three-dimensional velocity anomalies under a seismic array using first $P$ arrival times from local earthquakes, 1. A homogeneous initial model, $J$. Geophys. Res. 23, 4381-4399.

Birch, F. (1958). Interpretation of the seismie structure of the crust in the light of experimental studies of wave velocities in rocks, in Contributions in Geophysics in Honor of Beno Gutenberg, Pergamon Press, New York, 158-170.

Birch, F. (1960). The velocity of compressional waves in rocks to 10 kilobars, Part 1, J. Geophys. Res. $65,1083$.

Boore, D. M. and D. P. Hill (1973). Wave propagation characteristics in the vicinity of the San Andreas fault, Stanford Univ. Publ., Univ. Ser., Geol. Sci., 13, 215-225.

Engdahl, E. R. and W. H. K. Lee (1976). Relocation of local earthquakes by seismic ray tracing, J. Geophys. Res. 23, 4400-4406.

Healy, J. and L. Peake (1975). Seismic velocity structure along a section of the San Andreas fault near Bear Valley, California, Bull. Seism. Soc. Am. 65, 1177-1197.

Lachenbruch, A. H. and J. H. Sass (1973). Thermo-mechanical aspects of the San Andreas fault system, Stanford Univ. Publ., Univ. Ser., Geol. Sci., 13, 192-205.

Lin, Wu-nan (1977). Velocities of compressional waves in rocks at central California at high pressure and high temperature and application to the study of the crustal structure of California Coast Ranges, Ph.D. Dissertation, University of California, Berkeley, $185 \mathrm{pp}$.

McEvilly, T. V. (1966). Crustal structure estimation within a large scale array. Geophys. J. 11, 13-17.

McEvilly, T. V. (1966). The earthquake sequence of November 1964 near Corralitos, California, Bull. Seism. Soc. Am. 56, 755-773.

McEvilly, T. V. and R. W. Clymer (1975). A deep crustal reflection survey on the San Andreas Fault, EOS, Trans. Am. Geophys. Union 56, 1021.

McNally, K. C. (1978a). Uniform earthquake history reconstruction and seismicity 1936-1975: San Andreas fault, central California, Bull. Seism. Soc. Am. 68 (in press).

MeNally, K. C. (1978b). Patterns of earthquake clustering preceding moderate earthquakes, central California, Bull. Seism. Soc. Am. 68 (in press).

MeNally, K. C. (1978c). A statistical analysis of earthquake clustering, San Andreas fault, central California, Bull. Seism. Soc. Am. 68, submitted for publication. 
Nason, R. D. (1973). Fault creep and earthquakes on the San Andreas fault, Stanford Univ. Publ., Univ. Ser., Geol. Sci. 13, 275-285.

Stewart, S. W. (1968). Preliminary comparison of seismic travel times and inferred crustal structure adjacent to the San Andreas fault in the Diablo and Gabilan ranges of central California, Stanford Univ., Publ., Univ. Ser., Geol. Sci. 11, 218-230.

SEISMOGRAPHIC Station

Department of Geology and Geophysics

UNIVERSITY OF CALIFORNiA

Berkeley, California 94720

Manuscript received June 28, 1977 